\title{
Pengetahuan dan Beban Kerja Perawat Berhubungan Dengan Kelengkapan Pendokumentasian Asuhan Keperawatan di Bangsal Penyakit Dalam dan Bedah
}

\author{
Nursynta Kimalaha ${ }^{1}$, Mahfud ${ }^{1}$, Anggi Napida Anggraini ${ }^{1}$ \\ Universitas Alma Ata \\ Email: mahfud268@gmail.com
}

\begin{abstract}
Abstrak
Salah satu upaya dalam peningkatan mutu pelayanan keperawatan yaitu dengan melakukan pendokumentasian proses asuhan keperawatan. Penyebab terjadinya hal tersebut karena kurangnya pengetahuan dan beban kerja perawat yang berlebih. Penelitian ini dilakukan untuk Mengetahui hubungan pengetahuan dan beban kerja perawat dengan kelengkapan pengisian dokumentasi asuhan keperawatan di RSUD Dr. Tjitrowardojo Purworejo.Penelitian ini merupakan penelitian kuantitatif dengan menggunakan rancangan penelitiancross sectional. Populasi dalam penelitian ini adalah seluruh perawat dibangsal Penyakit Dalam dan Bedah di RSUD Dr. Tjitrowardojo Purworejo yang berjumlah 65 perawat. Pengambilan sampel dalam penelitian ini menggunakan teknik total sampling. Instrumen penelitian untuk pengetahuan dan beban kerja menggunakan kuesioner dan kelengkapan asuhan keperawatan menggunakan observasi. Data menggunakan uji statistik chi square. Hasil Penelitian didapatkan bahwa perawat dengan pengetahuan baik dalam mengisi dokumentasi asuhan keperawatan dalam kategori lengkap sejumlah 33 perawat $(50,77 \%)$. Menunjukkan bahwa ada hubungan yang diperoleh hasil $p=0.001 \quad(p<0,05)$ berarti ada hubungan antara pengetahuan dengan kelengkapan pendokumentasian asuhan keperawatan, dan perawat dengan beban kerja tinggi dalam mengisi dokumentasi asuhan keperawatan kurang lengkap sejumlah 20 perawat $(30,77 \%)$, dan diperoleh hasil $p=0.002$ $(p<0,05)$. Kesimpulanya ada hubungan antara beban kerja dengan kelengkapan pendokumentasian asuhan keperawatan.
\end{abstract}

Kata Kunci: Pengetahuan, Beban Kerja, Dokumentasi Asuhan Keperawatan

Knowledge and Nursing Employment Connections Related to Completion of The Documentation of Nursing Care In Inpatient Room of Disease And Surgery

\begin{abstract}
Abstrack
One effort in improving the quality of nursing care is to perform nursing care process documentation, but the documentation by the majority of nurses are still less than optimal. One cause of this happening due to lack of knowledge and the excessive workload of nurses. Knowing the relationship between knowledge and the workload of nurses with the completeness of the documentation of nursing care in hospitals Dr. Purworejo. a quantitative study using cross sectional design. The population in this study are all nurses dibangsal Medicine and Surgery at the Hospital Purworejo Dr. Tjitrowardojo totaling 65 nurses. The samples in this study using total sampling technique. The research instrument for knowledge and workloads using questionnaires and completeness of nursing care using observation. Data using the chi square test. Results showed that nurses with good knowledge in charge of nursing care documentation in the category complete a total of 33 nurses $(50.77 \%)$. Shows that there is a relationship which result $p=0.001(p<0.05)$ means that there is a relationship between knowledge with complete documentation of nursing care, and nurses with a high workload in charge of nursing care documentation incomplete number 20 nurses $(30.77 \%)$, and the result $p=0.002(p<0.05)$ means that there is a relationship between workload by the completeness of documentation of nursing care.
\end{abstract}

Keywords: Knowledge, Workload, Nursing Documentation

Received: 24/08/2018; published: 28/10/2018 


\section{PENDAHULUAN}

Pelayanan keperawatan merupakan salah satu faktor penentu baik buruknya mutu dan citra rumah sakit. Salah satu upaya peningkatan mutu pelayanan keperawatan yaitu melakukan pendokumentasian asuhan keperawatan yang dilakukan oleh perawat (1). Pendokumentasian merupakan unsur pokok dalam pertanggungjawaban kinerja profesi keperawatan setelah melakukan intervensi keperawatan langsung kepada pasien. Munculnya perkembangan teknologi informasi sesuai dengan perkembangan konsep dan tata cara berkomunikasi di bidang kesehatan

Dokumentasi adalah bagian dari keseluruhan tanggung jawab perawat untuk perawatan pasien. Catatan klinis memfasilitas pemberian keperawatan, meningkatkan kontinuitas perawatan, dan membantu mengkoordinasikan pengobatan dan evaluasi pasien (2). Pencatatan dokumentasi asuhan keperawatan menjadi kewajiban yang harus dilakukan oleh perawat. Kewajiban melakukan pencatatan dokumentasi asuhan keperawatan sudah tercantum dalam Keputusan Menteri Kesehatan Republik Indonesia tentang izin dan penyelengaraan praktik perawat yang menyatakan bahwa perawat wajib melakukan pencatatan keperawatan dengan sistematis, akan tetapi masih terdapat adanya ketidaklengkapan dalam pengisian dokumentasi asuhan keperawatan yang dilakukan oleh perawat di rumah sakit (5).

Pelaksanaan dokumentasi asuhan keperawatan di Indonesia masih belum dilakukan secara optimal. Hal ini didukung dengan penelitian Martini di RSUD kota Salatiga yang menunjukkan bahwa kelengkapan pengisian dokumentasi asuhan keperawatan untuk masing-masing tahap dalam asuhan keperawatan masih dibawah $70 \%$. Kelengkapan pendokumentasian terbesar terdapat pada pencatatan tindakan keperawatan 57,8\% dan terkecil pada perumusan diagnosa keperawatan 29,6\% (6). Hasil penelitian sebelumnya menunjukkan ketidaklengkapan pengisian dokumentasi asuhan keperawatan dilihat dari kunjungan pasien tahun 2014 berjumlah 2280 orang, sedangkan jumlah rekam medis yang tidak lengkap berjumlah 2250 (98,6\%) (7). Hasil penelitian di RSUD Wates juga menunjukkan masih terdapat dokumentasi keperawatan $77,5 \%$ dalam assesment pengkajian dokumentasi yang dilakukan perawat (8)

Semua data tersebut menunjukkan bahwa pelaksanaan pendokumentasian asuhan keperawatan masih tergolong tidak lengkap. Faktor-faktor yang mempengaruhi dalam pelaksanaan pendokumentasian asuhan keperawatan yaitu beban kerja perawat, sikap perawat, pengetahuan perawat, motivasi perawat dalam bekerja dan sarana prasarana yang terdapat di rumah sakit untuk mengoptimalkan kesembuhan klien. Seorang perawat mempunyai peran dalam melaksanakan pendokumentasian asuhan keperawatan (9). Dalam pelaksanaannya pengisian dokumentasi asuhan keperawatan pada dasarnya masih memiliki Kimalaha, N, Mahfud, Anggraini A.N, 2018. Indonesian Journal of Hospital Administration 
permasalahan, yaitu masih rendahnya tingkat pemahaman terhadap pendokumentasian asuhan keperawatan. Hal ini didukung dengan hasil penelitian di RSUP Sanglah Denpasar diperoleh responden dengan pengetahuan kurang dengan kelengkapan pendokumentasian tidak sesuai sebanyak 86,4\% (9). Adapun Faktor-faktor yang dapat mempengaruhi dalam pengisian dokumentasi asuhan keperawatan salah satunya disebabkan oleh beban kerja perawat.

Penelitian sebelumnya yang dilakukan oleh Mastini RSUP Sanglah Denpasar juga menunjukkan bahwa beban kerja ringan dengan kelengkapan pengisian dokumentasi asuhan keperawatan yang sesuai sebesar 90,4\% sedangkan beban kerja sedang dengan kelengkapan pengisian dokumentasi asuhan keperawatan yang tidak sesuai sebesar 95,8\% (9). Peneliti sebelum melakukan penelitian, melakukan studi pendahuluan terlebih dahulu yang berupa observasi dan wawancara dengan Kepala ruangan dan perawat bangsal penyakit dalam dan bedah pada hari rabu tanggal 09 november 2016 jam 14.10 WIB.

Peneliti mengobservasi 15 rekam medis pasien, terdapat 10 rekam medis yang tidak lengkap dalam pengisian dokumentasi asuhan keperawatan yang berhubungan dengan pengisian evaluasi SOAP yang masih terdapat ketidaklengkapan jam dan tanda tangan perawat, kemudian wawancara terhadap 5 perawat pertanyaannya mengenai pengetahuan dokumentasi asuhan keperawatan 3 perawat diantaranya masih menjawab dengan kurang lengkap, dan berdasarkan wawancara terhadap kepala ruangan dan 5 orang perawat mengenai beban kerja perawat yang dirasakan hasilnya mengatakan beban kerja tinggi, dikarenakan selain melakukan tugas pokok perawat dalam melakukan asuhan keperawatan seperti melakukan pelayanan keperawatan, perawat juga melakukan tugas lain seperti pendelegasian dokter yaitu memberikan obat, injeksi, perawat juga melakukan peranan sebagai tenaga administrasi dan tenaga farmasi, selain itu karena bangsal penyakit dalam dan bedah harus membutuhkan observasi yang ketat, sehingga waktu untuk beristirahat juga tergolong sedikit dan dapat mempengaruhi beban kerja di rumah sakit.

\section{BAHAN DAN METODE}

Jenis penelitian ini adalah penelitian kuantitatif dengan desain cross sectional. Populasi dalam penelitian ini adalah seluruh perawat di bangsal penyakit dalam dan bedah yang berjumlah 66 perawat. Pengambilan sampel mengunakan total sampling yaitu pengambilan sampel menggunakan semua populasi menjadi subjek. dengan kriteria inklusi dan ekslusi. Analisa data menggunakan chi square. Variabel independent penelitian ini yaitu pengetahuan dan beban kerja perawat, sedangkan variabel dependent yaitu kelengkapan pendokumentasian asuhan keperawatan. 


\section{HASIL DAN PEMBAHASAN}

Tabel 1. Distribusi Frekuensi Karakteristik Perawat di Bangsal Penyakit Dalam dan Bedah RSUD Dr.Tjitrowardojo Purworejo

\begin{tabular}{lcc}
\hline Karakteristik Perawat & $\mathbf{n}$ & Presentase (\%) \\
\hline Jenis Kelamin & & \\
Laki-laki & 15 & 23,1 \\
Perempuan & 50 & 76,9 \\
\hline Usia & & \\
20-30 tahun & 21 & 32,3 \\
31-40 tahun & 33 & 50,8 \\
$>40$ tahun & 11 & 16,9 \\
\hline Pendidikan & & \\
SPK & 1 & 1,5 \\
DIII & 45 & 69,2 \\
SI & 19 & 29,2 \\
\hline Masa kerja & & \\
1-5 tahun & 21 & 32,3 \\
6-10 tahun & 20 & 30,8 \\
11-20 tahun & 19 & 29,2 \\
$>20$ tahun & 5 & 7,7 \\
\hline Tugas Perawat & & \\
PA & 53 & 81,5 \\
PP & 12 & 18,5 \\
\hline Total & 65 & 100 \\
\hline
\end{tabular}

Pada Tabel 1 dapat menunjukan bahwa karakteristik jenis kelamin paling banyak yaitu perempuan sejumlah 50 perawat (76.9\%), Distribusi usia paling banyak antara 31-40 tahun sejumlah 33 perawat $(50.8 \%)$ dan perawat dengan usia paling sedikit yaitu>40 tahun sejumlah 11 perawat (16.9\%). Distribusi pendidikan paling banyak yaitu D3 sejumlah 45 perawat $(69.2 \%)$ dan pendidikan paling sedikit yaitu SPK sejumlah 1 perawat(1.5\%). Distribusi karakteristik masa kerja paling banyak antara 1-5 tahun sejumlah 21 perawat (32.3\%) dan perawat dengan masa kerja paling sedikit>20 tahun sebanyak 5 perawat(7.7\%). Distribusi karakteristik tugas perawat paling banyak PA sejumlah 53 responden (81.5\%).

Tabel 2. Distribusi Frekuensi Pengetahuan Perawat di Bangsal Penyakit Dalam dan Bedah RSUD Dr. Tjitrowardojo Purworejo

\begin{tabular}{lll}
\hline Pengetahuan & $\mathbf{n}$ & $\%$ \\
\hline Baik & 53 & 81,5 \\
Kurang & 12 & 18,5 \\
\hline Total & 65 & 100 \\
\hline
\end{tabular}

Sumber: Data Primer (2018) 
Pada tabel 2 menunjukan bahwa pengetahuan paling banyak kategori baik yaitu sejumlah 53 perawat $(81,5 \%)$.

Tabel 3. Distribusi Frekuensi berdasarkan Beban Kerja Perawat Bangsal Penyakit Dalam dan Bedah di RSUD Dr. Tjitrowardojo Purworejo

\begin{tabular}{lll}
\hline Beban Kerja & $\mathbf{n}$ & $\%$ \\
\hline Sangat tinggi & 14 & 21,5 \\
Tinggi & 34 & 52,3 \\
Agak tinggi & 17 & 26,2 \\
Sedang & 0 & 0 \\
Rendah & 0 & 0 \\
\hline Total & 65 & 100 \\
\hline
\end{tabular}

Sumber: Data Primer 2017

Pada Tabel 3 menunjukan bahwa beban kerja paling banyak kategori tinggi yaitu sejumlah 34 perawat (52.3\%) dan beban kerja paling sedikit kategori sangat tinggi sejumlah 17 perawat $(21.5 \%)$.

Tabel 4. Distribusi Frekuensi berdasarkan Kelengkapan Pendokumentasian Asuhan Keperawatan Bangsal Penyakit Dalam dan Bedah di RSUD Dr. Tjitrowardojo

$$
\text { Purworejo }
$$

\begin{tabular}{ccc}
\hline Dokumentasi & $\mathbf{n}$ & $\%$ \\
\hline Lengkap & 34 & 52.3 \\
Kurang Lengkap & 31 & 47.7 \\
\hline Total & 65 & 100 \\
\hline
\end{tabular}

\section{Sumber: Data Primer 2017}

Pada tabel 4 menunjukan bahwa kelengkapan pendokumentasian asuhan keperawatan paling banyak kategori lengkap yaitu sejumlah 34 responden (52.3\%).

Tabel 5. Hubungan Pengetahuan perawat dengan Kelengkapan Pendokumentasian Asuhan Keperawatan di RSUD Dr. Tjitrowardojo Purworejo

\begin{tabular}{lllllllc}
\hline Pengetahuan & \multicolumn{6}{c}{ Kelengkapan Dokumentasi Asuhan Keperawatan } \\
\cline { 2 - 7 } & \multicolumn{3}{c}{$\begin{array}{c}\text { Kurang } \\
\text { Lengkap }\end{array}$} & \multicolumn{2}{c}{ Lengkap } & Total & $\begin{array}{c}\mathrm{P} \\
\text { Valu }\end{array}$ \\
\cline { 2 - 7 } & $\mathrm{n}$ & $\%$ & $\mathrm{n}$ & $\%$ & $\mathrm{n}$ & $\%$ & $\mathrm{e}$ \\
\hline Kurang & 11 & 16,9 & 1 & 1,5 & 12 & $, 18,5$ & 0.00 \\
Baik & 20 & 30,8 & 33 & 50,8 & 53 & 81,5 & 1 \\
\hline \multicolumn{1}{c}{ Total } & 31 & 47,7 & 34 & 52,3 & 65 & 100 & \\
\hline
\end{tabular}

Sumber: Data Primer 2017

Pada Tabel 5 hubungan pengetahuan perawat dengan kelengkapan pendokumentasian asuhan keperawatan di bangsal penyakit dalam dan bedah yaitu didapatkan bahwa perawat dengan pengetahuan kurang dengan kelengkapan pendokumentasian asuhan keperawatan 
kurang lengkap yaitu 11 perawat ( 16,9\%), perawat dengan pengetahuan baik dengan kelengkapan pendokumentasian lengkap yaitu 33 perawat $(50,8 \%)$. Hasil uji chi square, pValue $=0,001 \quad(p<0,05)$ menunjukkan bahwa nilai $p<0,05$ berarti Ho ditolak dan Ha diterima artinya ada hubungan pengetahuan dengan kelengkapan pendokumentasian asuhan keperawatan.

Tabel 6 Hubungan Beban Kerja dengan Kelengkapan Pendokumentasian Asuhan Keperawatan Bangsal Penyakit Dalam dan Bedah di RSUD Dr. Tjitrowardojo

Purworejo

\begin{tabular}{|c|c|c|c|c|c|c|}
\hline \multirow[t]{3}{*}{ Beban Kerja } & \multicolumn{4}{|c|}{$\begin{array}{l}\text { Kelengkapan Dokumentasi Asuhan } \\
\text { Keperawatan }\end{array}$} & & \multirow[t]{2}{*}{$\begin{array}{l}\mathbf{p} \\
\text { Value }\end{array}$} \\
\hline & \multicolumn{2}{|c|}{$\begin{array}{l}\text { Kurang } \\
\text { Lengkap }\end{array}$} & \multicolumn{2}{|c|}{ Lengkap } & Total & \\
\hline & $n$ & $\%$ & $n$ & $\%$ & $\mathrm{n}$ & \\
\hline Agak Tinggi & 2 & 3,1 & 15 & 23,1 & $\begin{array}{l}17 \\
26,2\end{array}$ & 0.002 \\
\hline Tinggi & & 30,8 & 14 & 21,5 & $\begin{array}{l}34 \\
52,3\end{array}$ & \\
\hline Sangat Tinggi & 9 & 13,8 & 5 & 7,7 & $\begin{array}{l}14 \\
21,5\end{array}$ & \\
\hline Total & & 47,7 & 34 & 52,3 & $\begin{array}{l}65 \\
100\end{array}$ & \\
\hline
\end{tabular}

Sumber: Data Primer 2017

Pada Tabel 6 hubungan beban kerja perawat dengan kelengkapan pendokumentasian asuhan keperawatan di bangsal penyakit dalam dan bedah yaitu didapatkan bahwa Hasil uji chi square, pValue $=0,002 \quad(p<0,05)$ menunjukkan bahwa nilai $p<0,05$ berarti hipotesis diterima artinya ada hubungan beban kerja perawat dengan kelengkapan pendokumentasian asuhan keperawatan.

\section{Pembahasan}

Penelitian ini menunjukkan menunjukkan sebagian besar WUS berumur dewasa akhir (36-45) dan PUS berumur dewasa akhir (36-45), umur mempengaruhi dalam pengetahuan seperti dalam penelitian Alimatul Huda yang menyebutkan dalam penelitiannya pengetahuan tentang KB yang kurang-cukup yaitu umur $<20$ tahun dan $>35$ tahun sedangkan yang memiliki pengetahuan baik yaitu umur 20-35 tahun (8). Umur ideal untuk seorang ibu memiliki anak adalah 20-35 tahun, berdasarkan teori bahwa kehamilan berisiko dipengaruhi oleh umur. Hal ini dipengaruhi oleh perkembangan organ reproduksi perempuan dimana umur terlalu muda atau umur yang terlalu tua menjadi resiko karena dianggap alat reproduksi belum siap untuk hamil sehingga dapat menyebabkan kesakitan maupun kematian pada ibu dan juga janin (9). Pendapat serupa juga dikemukakan oleh Rizka yang menyatakan bahwa terdapat hubungan antara usia terhadap penggunaan alat kontrasepsi (10). 
Penelitian ini menunjukkan bahwa usia mempengaruhi kematangan pengetahuan tentang penggunaan alat kontrasepsi yang dinilai dari aspek kegunaan, kelebihan, kekurangan, efek samping dan jenisnya. Sebagian besar PUS beragama Islam, dimana di agama Islam meyakini istilah banyak anak banyak rezeki dan anak itu dianggap sebagai rezeki yang tidak boleh di tolak. Seperti yang disebutkan oleh Eva dalam penelitiannya bahwa agama tidak ada hubungan dengan keikutsertaan PUS dalam program KB (11). Tetapi dalam era kehidupan yang modern saat ini banyak pertimbangan dari PUS untuk memiliki jumlah anak dikarenakan jika PUS memiliki anak banyak ditakutkan akan memberartkan dalam perekonomian dari PUS itu sendiri karena akan menyangkut kehidupan kedepan dari sang anak seperti biaya pendidikan. Jadi dalam ajaran agama memperbolehkan PUS untuk menggunakan KB ditinjau dari manfaat dari KB itu sendiri.

Sebagian besar PUS berpendidikan terakhir SMA. Alimatul Huda menyatakan bahwa seseorang yang berpendidikan tinggi lebih banyak mengalami kejadian unmet need KB dikarenakan orang yang berpendidikan tinggi akan memberikan respon yang lebih rasional dari pada mereka yang berpendidikan rendah, lebih kreatif dan lebih terbuka terhadap usaha-usaha pembaruan (8). Pendapat serupa juga disampaikan oleh Beyna Handayani dalam penelitiannya yang menyatakan tidak ada hubungan yang signifikan antara pendidikan istri maupun suami dengan keikutsertaan KB (12). Pendapat lain juga disampaikan oleh Susiana dalam penelitiannya bahwa tidak ada hubungan antara tingkat pendidikan dengan motivasi pria PUS dalam menggunakan alat kontrasepsi (13). Berdasarkan pendapat Kartini, bahwa bukan berarti seseorang yang berpendidikan rendah maka akan memiliki pengetahuan yang rendah pula karena peningkatan pengetahuan seseorang tidak hanya diperoleh dari pendidikan formal saja akan tetapi diperoleh melalui pendidikan non formal, sehingga bisa saja seseorang dengan pendidikan rendah ataupun tinggi memutuskan sesuatu berdasarkan pengetahuan dan pengalaman (12). Pendidikan dapat mempengaruhi seseorang termasuk juga perilaku seseorang akan pola hidup terutama dalam memotivasi untuk sikap berperan serta dalam pembangunan. Pendidikan merupakan salah satu faktor yang dapat mempengaruhi pengetahuan dan sikap tentang metode kontrasepsi.

Sebagian besar WUS di Dusun Metes memiliki anak 2. Menurut Susiana dalam penelitiannya menyebutkan bahwa tidak ada hubungan antara jumlah anak masih hidup dengan kejadian unmet need KB (14). Jumlah dan jenis kelamin anak yang hidup memiliki pengaruh yang besar terhadap penerimaan metode KB. Semakin banyak jumlah anak masih hidup maka akan meningkatkan penggunaan kontrasepsi. Wanita yang memiliki satu orang anak yang hidup penggunaan alat kontrasepsi lebih rendah dibandingkan dengan yang memiliki jumlah anak dua atau lebih dari tiga orang anak. Wanita dengan jumlah anak 
yang sedikt memiliki keinginan untuk mendapatkan anak dengan jenis kelamin yang berbeda (14). Menurut Ubadiyah tidak ada hubungan antara anak yang masih hidup dengan kejadian unmet need KB (15). Hal ini menunjukkan bahwa jumlah anak tidak mempengaruhi seseorang untuk menggunakan alat kontrasepsi dekarenakan memiliki anak itu sesuai kemauan dari PUS sesuai dengan yang sudah di rencanakan oleh PUS sejak awal pernikahan.

\section{Hubungan Peran Tenaga Kesehatan dengan Kejadian Unmet Need KB dengan}

Penelitian ini menunjukkan sebagian besar responden beranggapan peran tenaga kesehatan di Dusun Metes sudah maksimal. Hasil bivariat menunjukkan ada hubungan antara peran tenaga kesehatan dengan kejadian unmet need KB di Dusun Metes Kelurahan Argorejo Sedayu Bantul. Keeratan hubungan antara peran tenaga kesehatan dengan kejadian unmet need KB di Dusun Metes Kelurahan Argorejo Sedayu Bantul menunjukan keeratan hubungan sangat rendah. Peran tenaga kesehatan merupakan faktor pendukung dari kejadian unmet need KB. Berdasarkan hasil analisis kuesioner, responden kurang maksimal mendapatkan penjelasan dari petugas kesehatan mengenai efek samping dan jangka waktu penggunaan KB sehingga masih ada responden yang tidak menggunakan alat kontrasepsi. Hasil penelitian ini menunjukkan bahwa peran tenga kesehatan bukan merupakan faktor yang dominan dalam kejadian unmet need KB karena sebagian besar responden merasa peran tenaga kesehatan sudah cukup maksimal.

Hasil penelitian ini didukung oleh penelitian Andari yang menyatakan ada hubungan antara peran tenaga kesehatan dengan perilaku penggunaan alat kontrasepsi (16). Petugas kesehatan merupakan pihak yang mengambil peran dalam tahap akhir pemakaian alat kontrasepsi calon akseptor keluarga berencana. Hasil penelitian yang dilakukan oleh Risa Fitriani juga menyatakan ada hubungan antara peran tenaga kesehatan dengan penggunaan kontrasepsi IUD. Risa berpendapat bahwa ibu yang kurang mendapatkan peran tenaga kesehatan lebih berisiko 8 kali tidak menggunakan IUD dari pada ibu yang mendapatkan peran tenaga kesehatan (17). Menurut Notoadmojo, bahwa sikap dan perilaku tenaga kesehatan merupakan pendorong atau penguat perilaku sehat pada masyarakat untuk mencapai kesehatan, maka tenaga kesehatan harus memperoleh pendidikan pelatihan khusus tentang kesehatan tentang ilmu perilaku kesehatan (18).

Peran tenaga kesehatan sangat dibutuhkan untuk menghindari terjadinya kejadian unmet need KB. Peran tenaga kesehatan yang dibutuhkan masyarakat yaitu pelaksana yang merupakan pelaksana dalam melakukan penyuluhan maupun pemasangan alat kontrasepsi. Pendidik yaitu memberikan pendidikan atau penyuluhan mengenai alat kontrasepsi. Peningkatan pengetahuan pada calon akseptor maupun akseptor KB adalah tugas dari tenaga kesehatan. Konsultan yaitu menjadi tempat konsultasi terhadap masalah 
pemilihan alat kontrasepsi yang akan digunakan baik suami maupun istri. Dengan memberikan pendidikan saja tidak cukup bagi tenaga kesehatan, dengan demikian seorang tenaga kesehatan harus mampu memberikan konseling dengan benar kepada calon akseptor maupun kepada akseptor. Berdasarkan penelitian didapatkan bahwa pengetahuan akseptor tentang KB suntik 3 bulan tidak berhubungan dengan ketepatan kunjungan ulang (19).

Hal ini menunjukkan bahwa tidak hanya edukasi yang dibutuhkan oleh wanita usia subur terkait dengan KB, namun lebih dari itu salah satunya adalah konseling. Kolaborator yaitu setiap tenaga kesehatan bisa saling berkolaborasi dalam proses pelayanan terhadap masyarakat. Koordinator yaitu peran yang mengarahkan, merencanakan serta mengorganisasi pelayanan kesehatan dari tim kesehatan sehingga saat memberikan pelayanan kesehatan terhadap masyarakat dapat terarah serta sesuai dengan kebutuhan masyarakat (20). Sesuai dengan program pemerintah yaitu tenaga kesehatan harus melakukan pendidikan kesehatan berupa penyuluhan mengenai KB kepada seluruh WUS supaya kehamilannya bisa terkontrol.

\section{SIMPULAN DAN SARAN}

Berdasarkan hasil penelitian yang dilakukan dapat ditarik kesimpulan sebagai berikut: Karakteristik perawat di bangsal penyakit dalam dan bedah RSUD Dr. Tjitrowardojo Purworejo paling terbanyak sesuai jenis kelamin perempuan, Usia 31-40, Pendidikan DIII keperawatan, Masa kerja 1-5 tahun, dan tugas perawat PA. Pengetahuan perawat di bangsal penyakit dalam dan bedah RSUD Dr. Tjitrowardojo Purworejo memiliki pengetahuan baik. Beban kerja perawat di bangsal penyakit dalam dan bedah RSUD Dr. Tjitrowardojo Purworejo memiliki beban kerja tinggi. Kelengkapan pengisian dokumentasi asuhan keperawatan di bangsal penyakit dalam dan bedah RSUD Dr. Tjitrowardojo Purworejo termasuk dalam kategori lengkap. Ada hubungan pengetahuan dengan kelengkapan pendokumentasian asuhan keperawatan di bangsal penyakit dalam dan bedah RSUD Dr. Tjitrowardojo Purworejo. Ada hubungan beban kerja dengan kelengkapan pendokumentasian asuhan keperawatan di bangsal penyakit dalam dan bedah RSUD Dr. Tjitrowardojo Purworejo.

\section{DAFTAR PUSTAKA}

1. Muninjaya, Gde AA. Manajemen Mutu Pelayanan Kesehatan, Jakarta: EGC;2011

2. Depkes RI. Standar Pelayanan dan Asuhan Keperawatan di Rumah Sakit. Jakarta: Departemen Kesehatan Rl;2004.

3. Martini. Hubungan karakteristik perawat, sikap, beban kerja, ketersediaan fasilitas dengan pendokumentasian asuhan keperawatan di ruang rawat inap RSUD kota salatiga. Tesis. http://eprints.undip.ac.id/18127/1/MARTINI.pdf. diakses pada tanggal 17 November 2016 pukul 18.40 WIB;2016. 
4. Tamaka. Hubungan antara beban kerja dengan pendokumentasian asuhan keperawatan di instalasi gawat darurat medik RSUP.Prof.Dr.R.D Kandou Manado. http://ejournal.unsrat.ac.id/index.php/jkp/article/view/8180/7736 diakses pada tanggal 17 November pukul 18.19 WIB;2016.

5. Notoatmodjo, S. Pendidikan dan Perilaku Kesehatan. Jakarta: Rineka Cipta;2003. Notoatmodjo, S. Pendidikan dan Perilaku kesehatan. Cetakan 2 Jakarta: PT. Rineka Cipta;2007.

6. Gaffar, L.O.J. Keperawatan Profesional. Jakarta: EGC;2009.

7. Kusnanto. Profesi dan Praktek Keperawatan Profesional. Jakarta: EGc;2008

8. Kurniawandari, E., \& Fatimah, F. S. Implementation of Documentation of Nursing Care in Wates Hospital. Jurnal Ners dan Kebidanan Indonesia, 6(2), 68-75. 2019.

9. Hariyono. "Hubungan antara beban kerja, stress kerja dan tingkat konflik dengan kelelahan kerja perawat di Rumah Sakit Islam Yogyakarta PDHIKotaYogyakarta“'.http://journal.uad.ac.id/index.php/KesMas/article/download/1107/p df29 diakses pada tanggal 17 November pukul 18.50 WIB; 2016

10. Nursalam. Proses dan Dokumentasi Keperawatan: Konsep dan Praktik. Jakarta: Salemba Medika;2013.

11. Budiono. Konsep Dasar Keperawatan. Jakarta: Bumi Medika; 2015.

12. Arwani, Supriyatno. Managemen Bangsal Keperawatan. Jakarta: EGC; 2006.

13. Notoadmodjo, Soekadjo. Promosi Kesehatan dan Perilaku Kesehatan. Jakarta: Rineka Cipta;2012.

14. Marquis BL, Huston CJ. Kepemimpinan dan Managemen, teori dan aplikasi, Ahli bahasa: Widyawati dan Handayani. Jakarta, Edisi 4, EGC; 2010.

15. Moekijat.Latihan dan Pengembangan Sumber Daya Manusia. Bandung: Mandar Maju;2006.

16. Hancock, P.A. \& Meshkati, N. Human Mental Workload. Elsevier,1988.

17. Winarti. Hubungan Beban Kerja Perawat Dengan Pelaksanaan Dan Pendokumentasian Asuhan Keperawatan Di lcu Rs Pku Muhammadiyah Yogyakarta. 2005

18. http://opac.unisayogya.ac.id/258/1/naskah\%20publikasi\%20winda.pdf.diakses pada tanggal 06 februari 2017.

19. Swastika. Hubungan Antara Pengetahuan Perawat Tentang Rekam Medis Dan Dokumentasi Keperawatan Dengan Kelengkapan Pencatatan Dokumentasi Keperawatan Di Rumah Sakit Mulia Hati Wonogiri. 2015.

20. Haris A. Hubungan Antara Beban Kerja Dengan Kelengkapan Pendokumentasian Asuhan Keperawatan Di Rumah Sakit Umum Sayang Rakyat Makassar. http://docplayer.info/34488686- diakse pada tanggal 06 februari 2017. 